Article

\title{
Implementation of the Sono-Heat-Exchanger in the Extra Virgin Olive Oil Extraction Process: End-User Validation and Analytical Evaluation
}

\author{
Lorenzo Cecchi $^{1,+}\left(\mathbb{D}\right.$, Maria Bellumori ${ }^{1,+}$, Filomena Corbo ${ }^{2} \mathbb{D}$, Gualtiero Milani ${ }^{2}$, \\ Maria Lisa Clodoveo ${ }^{3, *(\mathbb{D})}$ and Nadia Mulinacci ${ }^{1, *}$ \\ 1 Department of NEUROFARBA, and Multidisciplinary Centre of Research on Food Sciences (M.C.R.F.S.- \\ Ce.R.A.), University of Florence, Via Ugo Schiff 6, 50019 Sesto F.no Firenze, Italy \\ 2 Department of Pharmacy-Pharmaceutical Sciences, University Aldo Moro-Bari, Via Orabona, 4, \\ 70100 Bari, Italy \\ 3 Interdisciplinary Department of Medicine, University of Bari, Piazza Giulio Cesare, 11-70124 Bari, Italy \\ * Correspondence: marialisa.clodoveo@uniba.it (M.L.C.); nadia.mulinacci@unifi.it (N.M.); \\ Tel.: +39-0805442832 (M.L.C.); +39-0554573773 (N.M.) \\ + These authors contributed equally to this work.
}

Received: 30 May 2019; Accepted: 26 June 2019; Published: 27 June 2019

\begin{abstract}
The use of innovative systems, such as the heat exchanger, for production of extra virgin olive oil should allow maintenance of the same quality of those oils derived from traditional processes, and presents specific advantages. The performance of this system was evaluated by (i) determining the parameters directly measurable by the olive millers (i.e., end-user validation based on the production yields when the plant is located in different processing lines) and (ii) assessing the product quality through estimation of the content of phenolic and volatile compounds. The phenols were determined by High Performance Liquid Chromatography with Diode Array Detector (HPLC-DAD) before and after acidic hydrolysis while the volatile fraction was studied by Head-Space Solid-Phase-Micro-Extraction Gas-Chromatography with Mass Detector (HS-SPME-GC-MS). The use of the sono-heat-exchanger presents several advantages: it is a flexible machine, able to interface with all devices of the world's leading manufacturers of the Extra Virgin Olive Oil (EVOO) extraction plant, and it guarantees shorter processing times and energy savings. Our results also pointed out its capability to increase the oil yields up to $5.5 \%$, particularly when it extracts oil from unripe fruits, which in traditional processes yield oils with higher phenolic contents, but with lower oil yields. Overall, the quality of virgin olive oils was maintained, avoiding decreases of phenolic content or detrimental effects on the sensory characteristics.
\end{abstract}

Keywords: ultrasounds; end-user validation; hydroxytyrosol; phenolic compounds; volatile compounds; HS-SPME-GC-MS; HPLC-DAD; oil yields

\section{Introduction}

The involvement of end-users, namely the olive millers, in the development of innovative mechanical devices is fundamental in order to accelerate the transfer of research results and determine a change to the production system of extra virgin olive oil (EVOO) [1]. Indeed, only after process qualification has been completed can the manufacturing process begin production for commercial use [2]. Process qualification is the second stage of process validation [3] and concerns the qualification of manufacturing and production processes to confirm they are able to operate at a certain standard during sustained commercial manufacturing. The process validation of a technology represents an important step to move from an innovative idea to the diffusion of the new technology and its 
application in the reference-manufacturing context through a validation process. The purpose of the validation is to provide documented evidence to demonstrate with confidence that a specific process allows the constant production of a product that meets its predefined specifications and quality attributes [4].

Process qualification of industrial implementation of the sono-heat-exchanger in the EVOO extraction process has been discussed partially in previous papers covering the following aspects of manufacturing: (i) consumption of direct material, (ii) production times [5], (iii) labor [6], job security [7], (iv) occupied spaces [8], (v) energy consumption [9], (vi) investment/plant management costs [10], (vii) decrease in lead time, i.e., the time taken by the material to enter the raw warehouse and exit the finished warehouse [11].

The experimental phase of this work consists of the qualification of the processes aimed to cover other aspects of process qualification of the industrial implementation of the sono-heat-exchanger in the EVOO extraction process: (i) quality and stability of the process and (ii) higher and constant quality of the finished product.

During this phase, it is important to determine if the process is able to produce, in a reproducible way, a high amount of high quality EVOO through the simultaneous administration of both ultrasonic and thermal energy to the olive paste.

The objective of measuring of the performance of the innovative system was achieved through two strategies: (i) evaluating the results directly perceptible and measurable by the olive millers (i.e., end-user validation based on the estimate of production yields when the plant is located in processing lines that differ in brand, technology, and work capacity, using olives characterized by different cultivars and maturation indices); (ii) assessing the product quality through estimation of the content of phenolic and volatile compounds. Achieving these two objectives required a multidisciplinary approach [12].

The interdisciplinary research activity is essential to transfer to the olive oil industry the most recent technologies useful for supporting the income of the millers, increasing simultaneously the quantity of extractable oil from the olives and its quality in terms of concentration of healthy molecules with different pharmacological profiles [13].

The implementation of the first industrial-scale plant prototype in the olive oil extraction process combines two technologies: the ultrasounds and the heat exchanger, which is able to heat and cool oil pastes. This prototype is characterized by a high level of technological maturity (TRL, technology readiness levels), i.e., 7, which corresponds to the development of the system and which must conduct its validation based on an end-user validation protocol. This latter step is crucial as it allows the researcher not only to understand if the innovation meets the real needs of those who will be its users (the millers), but also to have useful opinions for optimization directly from the insiders of a specific sector [14].

End-user validation is the best strategy to transform a technology into something that really meets the needs of the olive oil sector, determining the desired changes in the value of the product (i.e., a hydroxytyrosol content coherent with the application of health claims approved by the European Food Safety Authority (EFSA)) and in the income of the producers (due to the premium price gained by the high quality market segment) $[15,16]$.

Technology validation and technology transfer are indispensable factors for ferrying modern mills towards greater competitiveness in the global market based on two fundamental principles: producing higher quantities of oil and obtaining products of superior quality $[17,18]$. The achievement of the TRL 9, i.e., the technology in its final form, still requires some efforts that are only possible with the collaboration of the millers, who are able, from the height of their experience, to suggest ways of continuous improvement also in relation to the organoleptic characteristics desired in the product.

The aim of the work was to validate the application of ultrasound in the EVOO extraction process in order to ascertain if, when the system prototype is placed in the operational environment, the innovative method is able to increase oil yields, reduce the process time, and guarantee oil quality preservation. Several batches of olives of several cultivars, grown in different geographical areas from the Apulia region in 2017 and harvested at different maturation indexes, were selected to 
produce the 23 oils analyzed in this work. The analytical investigations were applied to all the EVOOs produced from the same batches of olives, with and without the use of ultrasounds. In particular, for the analysis of phenolic profiles, we used the official method of the International Olive Council (IOC) [19] improved by acid hydrolysis of the hydroalcoholic extract [20,21] and recently validated after these modifications [22,23]. The analysis of volatile compounds by HS-SPME-GC-MS [24] has been performed in order to assess if the introduction of ultrasound can induce a damage of the enzymatic complex of the lipoxygenase (LOX) pathway with a detrimental effect on the sensory characteristics of the product.

\section{Results and Discussion}

\subsection{Usability of the Sono-Heat-Exchanger (SHE) and Oil Yields}

Prototype development requires identification and control of risks that arise from a specific context of use and the characteristics of the user (for example level of education, and intellectual and technical skills). In order to demonstrate that these requirements are satisfied, it is necessary to validate usability. The IEC (International Electrotechnical Commission) 62,366 and the Human Factors Engineering Guidance Document of the FDA [25] provide guidance on how this validation must be carried out. It is required that the representative users (olive millers) are involved and the protocol is applied in its representative context of use (usage environment; the olive mill). Indeed, it is necessary to run through the core tasks within a participatory observation of genuine users in an actual or simulated user environment and let the security functions run. Only when users are able to achieve the targets, thus proving that user requirements are met, is the usability of product validated. To this aim, three different olive millers and mills were selected to test the performance of the sono-heat-exchanger (SHE). The oils were produced by processing olive fruits of cultivars collected from several geographical areas in the Apulia region, and with a different maturity index, according to data shown in Tables 1 and 2 and in Figure 1.

The SHE is essentially a piping through which the olive paste passes. If the heat pump and the driver are turned off, it is a simple through pipe, while, if they are turned on, the olive paste is simultaneously subjected to the exchange of thermal and ultrasonic energy. Therefore, in order to assess the effect of the innovative SHE system on the quantity and quality of the extracted EVOO, batches of olives were selected considering cultivar, harvesting area, and ripeness index. Each batch was divided into identical portions and processed both with and without ultrasounds, at a temperature of $24{ }^{\circ} \mathrm{C}$, according to a randomized scheme. The malaxation was not applied when the SHE turned on and this part of the plant was used only to transit the product into the decanter. The oil yields were calculated as the difference from the total oil content in the fruit and the total oil content in the olive pomace; it ranged from $12.1 \%$ to $24.1 \%$ depending on the cultivar and the maturity index of the olives, as shown in Figure 1. When applying ultrasound during milling, the oil extraction yields were always higher than those derived by the traditional process. Furthermore, combining the results shown in Figure 2 and the maturity index in Table 1, it is clear that the positive effect of the ultrasound treatment on oil yields was more evident when the olives were unripe than after fruit ripening. Indeed, it is more difficult to extract oil from green firm olives since the oil is contained in the cell vacuoles, which are not so easy to rupture. Ripening of fleshy olive fruit is one of the lasts developmental phases of fruit ontogeny, and it involves many changes including the accumulation of pigments and sugars and the process of flesh softening allowing an easier release of oil from very ripe fruits. Another interesting aspect is that the oils extracted from green fruits contain higher amounts of phenolic compounds, which increase the shelf life and the health quality of the EVOO, also increasing its commercial value. Having available a technology that allows the miller to anticipate the harvest without penalizing yields, reducing production times and obtaining an oil with a higher market value, contributes to increased profits and improved income. It has been previously demonstrated the use of the sono-heat-exchanger during milling allows energy savings [1,9]. 
Table 1. List of the analyzed extra virgin olive oils (EVOOs) produced in the different mills with (U) and without $(\mathrm{N})$ the use of ultrasounds. Oils from the same mill were produced on the same days.

\begin{tabular}{|c|c|c|c|c|c|c|c|}
\hline $\mathbf{n}^{\circ}$ & Sample & Cultivar & Olive Mill & Crusher & MI & $\begin{array}{l}\% \text { of Fruit Oil } \\
\text { Content in } \\
\text { the Fresh Matter }\end{array}$ & $\begin{array}{l}\% \text { of Pomace Oil } \\
\text { Content in } \\
\text { the Fresh Matter }\end{array}$ \\
\hline 1 & OM-N & Coratina & Mimì & $\begin{array}{l}\text { Hammer } \\
\text { Crusher }\end{array}$ & 1 & $19.6=0.6$ & $7.5=0.5$ \\
\hline 2 & OM-U & Coratina & Mimì & $\begin{array}{l}\text { Hammer } \\
\text { Crusher }\end{array}$ & 1 & $19.6=0.6$ & $2.0=0.6$ \\
\hline 3 & $1 \mathrm{~N}$ & Peranzana & \multirow{6}{*}{ Graco } & \multirow{6}{*}{ De-stoner } & \multirow{6}{*}{3} & \multirow{6}{*}{$24.8=0.4$} & \multirow{6}{*}{$5.1=0.4$} \\
\hline 4 & $3 N$ & Peranzana & & & & & \\
\hline 5 & $5 \mathrm{~N}$ & Peranzana & & & & & \\
\hline 6 & $9 \mathrm{~N}$ & Peranzana & & & & & \\
\hline 7 & $10 \mathrm{~N}$ & Peranzana & & & & & \\
\hline 8 & $12 \mathrm{~N}$ & Peranzana & & & & & \\
\hline 9 & $2 U$ & Peranzana & \multirow{6}{*}{ Graco } & \multirow{6}{*}{ De-stoner } & \multirow{6}{*}{3} & \multirow{6}{*}{$24.8=0.4$} & \multirow{6}{*}{$0.7=0.5$} \\
\hline 10 & $4 \mathrm{U}$ & Peranzana & & & & & \\
\hline 11 & $6 \mathrm{U}$ & Peranzana & & & & & \\
\hline 12 & $7 \mathrm{U}$ & Peranzana & & & & & \\
\hline 13 & $8 \mathrm{U}$ & Peranzana & & & & & \\
\hline 14 & $11 \mathrm{U}$ & Peranzana & & & & & \\
\hline 15 & $\mathrm{P} 5 \mathrm{~N}$ & Coratina/Ogliarola & \multirow[b]{2}{*}{ Frantolio } & Hammer & \multirow[b]{2}{*}{4} & \multirow[b]{2}{*}{$21.0=0.4$} & \multirow[b]{2}{*}{$1.8=0.4$} \\
\hline 16 & P6N & Coratina/Ogliarola & & Crusher & & & \\
\hline 17 & P3U & Coratina/Ogliarola & \multirow{3}{*}{ Frantolio } & \multirow{3}{*}{$\begin{array}{l}\text { Hammer } \\
\text { Crusher }\end{array}$} & \multirow{3}{*}{4} & \multirow{3}{*}{$21.0=0.4$} & \multirow{3}{*}{$0.7=0.2$} \\
\hline 18 & P4U & Coratina/Ogliarola & & & & & \\
\hline 19 & P7U & Coratina/Ogliarola & & & & & \\
\hline 20 & $\mathrm{C} 4 \mathrm{~N}$ & Cellina di Nardò & Frantolio & $\begin{array}{l}\text { Hammer } \\
\text { Crusher }\end{array}$ & 6 & $14.8=0.3$ & $1.6=0.4$ \\
\hline 21 & $\mathrm{C} 3 \mathrm{U}$ & Cellina di Nardò & \multirow{3}{*}{ Frantolio } & \multirow{3}{*}{$\begin{array}{l}\text { Hammer } \\
\text { Crusher }\end{array}$} & \multirow{3}{*}{6} & \multirow{3}{*}{$14.8=0.3$} & \multirow{3}{*}{$0.8=0.3$} \\
\hline 22 & C5U & Cellina di Nardò & & & & & \\
\hline 23 & C6U & Cellina di Nardò & & & & & \\
\hline
\end{tabular}

Table 2. Maturity index (MI) classification groups of olives based on skin and flesh color.

\begin{tabular}{|c|c|c|c|c|c|c|c|c|}
\hline $\begin{array}{c}\text { Maturity } \\
\text { Index Group }\end{array}$ & 0 & 1 & 2 & 3 & 4 & 5 & 6 & 7 \\
\hline & $\begin{array}{l}\text { Skin color } \\
\text { deep green }\end{array}$ & $\begin{array}{c}\text { Skin color } \\
\text { yellow-green }\end{array}$ & $\begin{array}{l}\text { Skin color with } \\
\text { <half the fruit } \\
\text { surface } \\
\text { turning red, } \\
\text { purple, or } \\
\text { black }\end{array}$ & $\begin{array}{l}\text { Skin color with } \\
\text { > half the fruit } \\
\text { surface } \\
\text { turning red, } \\
\text { purple, or } \\
\text { black }\end{array}$ & $\begin{array}{l}\text { Skin color all } \\
\text { purple or black } \\
\text { with all white } \\
\text { or green flesh }\end{array}$ & $\begin{array}{l}\text { Skin color all } \\
\text { purple or black } \\
\text { with < half } \\
\text { the flesh } \\
\text { turning purple }\end{array}$ & $\begin{array}{l}\text { Color all } \\
\text { purple or black } \\
\text { with }>\text { half } \\
\text { the flesh } \\
\text { turning purple }\end{array}$ & $\begin{array}{c}\text { Skin color all } \\
\text { purple or black } \\
\text { with all } \\
\text { the flesh } \\
\text { purple to } \\
\text { the pit }\end{array}$ \\
\hline
\end{tabular}

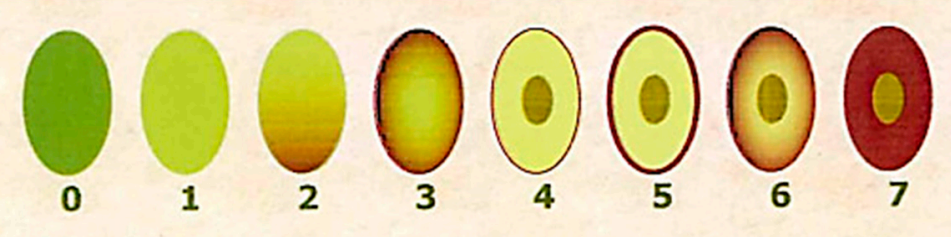

Figure 1. Ripening index according to the different color of the fruit.

\subsection{Determination of Phenolic Compounds}

Each mill produced several batches of oils both with and without applying the SHE (Table 1). After evaluation of oil yields, the phenolic and volatile fractions of samples were analyzed and the sensorial characteristics were evaluated by expert panelists (data not shown), to confirm they belonged to the extra virgin category. These analyses were selected for defining the final quality of the produced oils. 
The total phenolic amount was determined according to the IOC method and then the sum of hydroxytyrosol and tyrosol was evaluated after acidic hydrolysis applying the validated method [23]. The values obtained before and after hydrolysis are compared in Figure 3A, while the mean values obtained for each group of oils from different mills are compared in Figure 3B. As expected, the richest variety in terms of phenolic compounds was Coratina (samples OMU and OMN) followed by the Coratina-Ogliarola blend (samples P6N and P7U), while the lowest values were obtained for oils derived by Cellina di Nardò (C3U, C6U, C5U, and C4N). Overall, the values of total phenols varied in a wide range, showing concentrations from $58 \mathrm{mg} / \mathrm{kg}$ to $510 \mathrm{mg} / \mathrm{kg}$. For fresh EVOOs, the amount of free hydroxytyrosol and tyrosol was negligible in most of the samples, while an average concentration of $14.5 \mathrm{mg} / \mathrm{kg}$ was observed only for samples from Coratina and the Coratina-Ogliarola blend (data not shown).

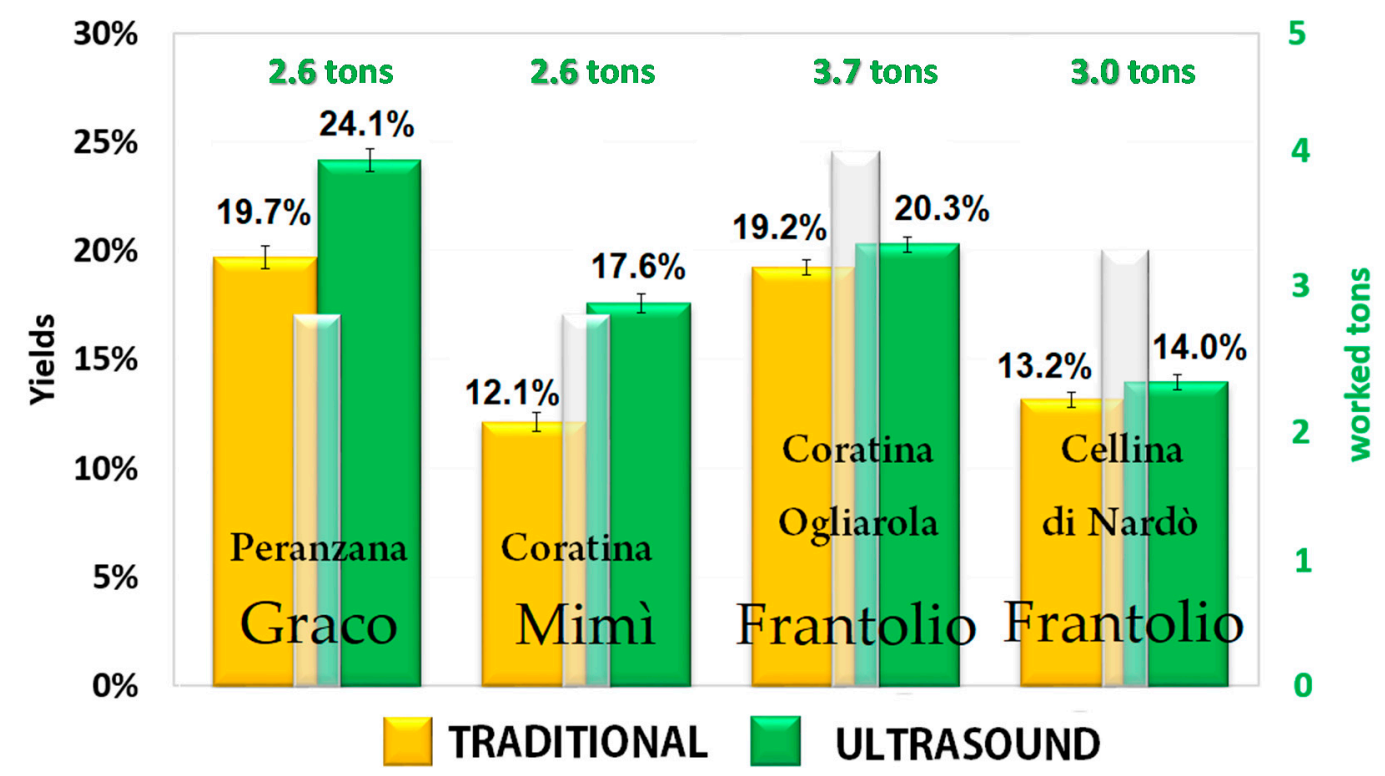

Figure 2. Mean oil yields obtained in the different oil mills, according to Table 1 . The white bars indicate the tons of milled olives; the yellow and green bars indicate the oil yields obtained with and without the use of the sono-heat-exchanger (SHE), respectively. 

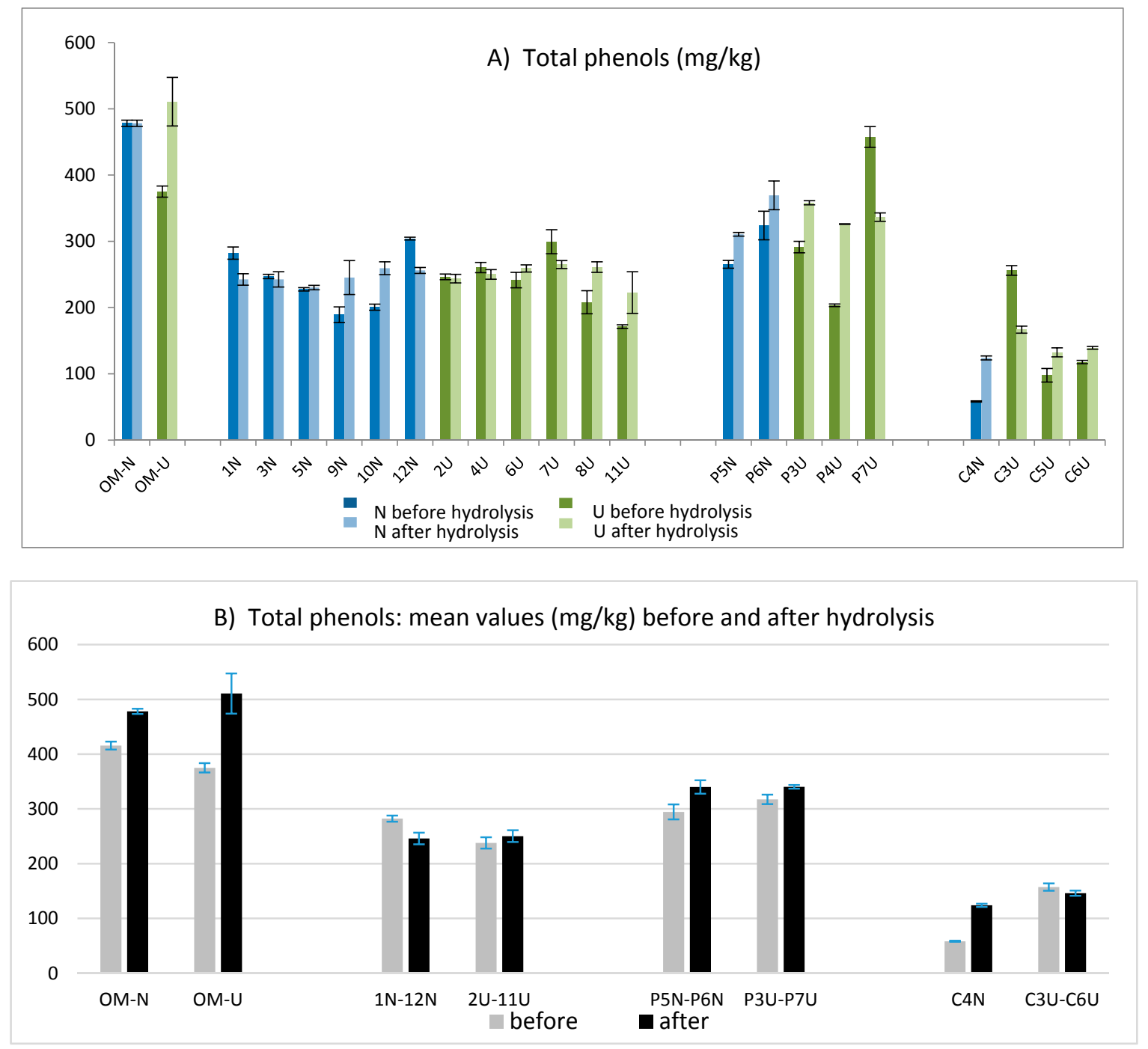

Figure 3. Total phenols obtained before and after the acidic hydrolysis for each EVOO (A) and averaged over all oils obtained in each oil mill (B).

The hydrolysis was applied to obtain a more accurate determination of the total tyrosol and hydroxytyrosol (free and linked forms) derived from their secoiridoidic precursors [23]. This approach, already applied in previous works [20-22], helped to better estimate the antioxidant potential of the analyzed oils. Comparing the amount of total phenols obtained before and after hydrolysis, the main differences were highlighted only for few samples: OMU, P4U, P7U, and C3U (Figure 3A). Data obtained before and after the hydrolysis showed a wide variability in terms of total phenols, ranging from values lower than $100 \mathrm{mg} / \mathrm{kg}$ (C4N before hydrolysis) to values higher than $500 \mathrm{mg} / \mathrm{kg}$ (OMU after hydrolysis). The results in Figure 3B pointed out that no significant differences were found between the EVOOs obtained from a traditional technology $(\mathrm{N})$ and those obtained by the help of ultrasounds (U).

Figure 4 shows the percentages of hydroxytyrosol in the sum of tyrosol and hydroxytyrosol. It emerges that the percentages of hydroxytyrosol ranged from $30 \%$ to $45 \%$ for most of samples, with exceptions only pointed out for oils from Cellina di Nardò cv (C4NI, C5UI, C3UI, C6UI), which showed lower percentages $(10 \%-25 \%)$. Unlike expected, the results obtained after hydrolysis suggested that the main secoiridoidic components of the virgin olive oils were not oleuropein derivatives, but ligstroside analogues, which contain tyrosol in their structures. Recent findings, obtained by applying the same hydrolytic method on virgin oils from various provenance and varieties [22,23], 
highlighted that the most of oils showed hydroxytyrosol below $50 \%$, confirming the prevalence of tyrosol precursors. In another study, it was proposed to sum the tyrosol derivatives and the hydroxytyrosol ones in order to evaluate the total useful phenolic content to apply the EFSA health claims [26]. The application of the acidic hydrolysis on a larger number of oils will help to acquire a more realistic picture of the secoiridoid pool in virgin olive oils.

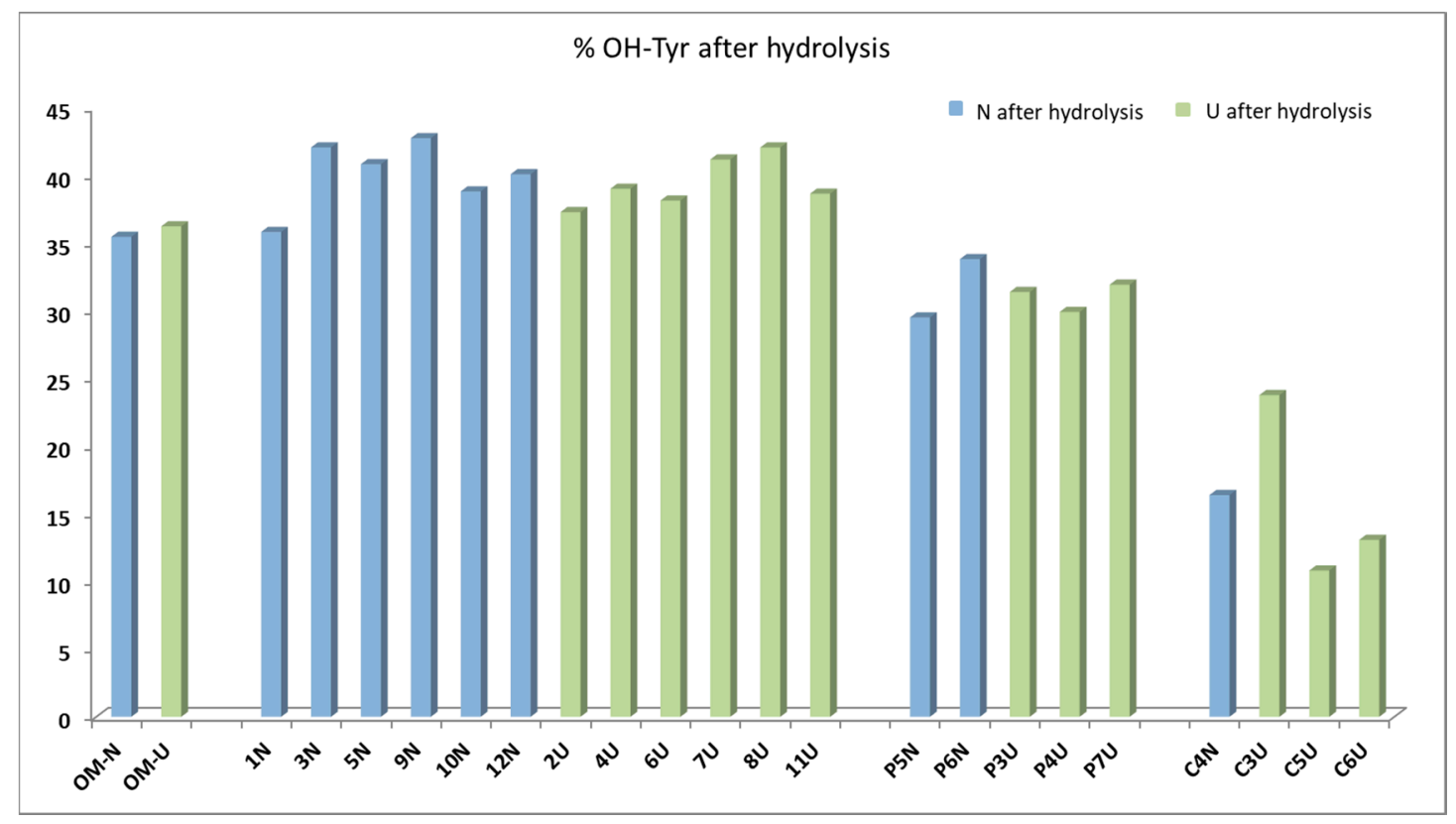

Figure 4. Hydroxytyrosol percentages evaluated after the acidic hydrolysis for the 23 oils and expressed on the sum of tyrosol and hydroxytyrosol.

\subsection{Effect of US on Volatile Organic Compounds}

The sensorial properties of virgin olive oils are crucial for defining the quality of the product [24], thus the content of the volatile organic compounds (VOCs) present in the headspace of our samples was determined by HS-SPME-GC-MS. Table 3 shows the content of two groups of VOCs in our samples, selected according to the literature: the first group (first 5 rows in Table 3) is constituted of the molecules originating in the LOX pathway, which are typically associated with the green and fruity notes of virgin olive oils (positive attributes); the second one (last 3 rows in Table 3) is represented by the C7 to C10 aldehydes, both saturated and unsaturated, which are linked to oxidative defects of virgin olive oils [27].

Table 3. Distribution of the different groups of volatiles produced during the lipoxygenase cascade (first 5 rows) and linked to oxidative defects (last 3 rows) in oils obtained with (U) and without (N) the use of SHE. For each couple of oils, no differences were highlighted as indicated by the same letter (a).

\begin{tabular}{cccccccccc}
\hline \multirow{2}{*}{ VOC } & \multicolumn{2}{c}{$\mathbf{1 N - 1 2 N}$} & \multicolumn{2}{c}{ P3U-P7U } & \multicolumn{2}{c}{ C3U-C6U } & \multicolumn{2}{c}{ OMN-OMU } \\
& $\mathbf{U}$ & $\mathbf{N}$ & $\mathbf{U}$ & $\mathbf{N}$ & $\mathbf{U}$ & $\mathbf{N}$ & $\mathbf{U}$ & $\mathbf{N}$ \\
\hline LOX C5 & $0.25 \mathrm{a}$ & $0.25 \mathrm{a}$ & $0.47 \mathrm{a}$ & $0.53 \mathrm{a}$ & $0.15 \mathrm{a}$ & $0.14 \mathrm{a}$ & $1.61 \mathrm{a}$ & $1.46 \mathrm{a}$ \\
LOX C6 aldehydes & $7.98 \mathrm{a}$ & $8.24 \mathrm{a}$ & $11.98 \mathrm{a}$ & $12.06 \mathrm{a}$ & $5.22 \mathrm{a}$ & $5.16 \mathrm{a}$ & $34.24 \mathrm{a}$ & $34.78 \mathrm{a}$ \\
LOX C6 esters & $2.91 \mathrm{a}$ & $2.89 \mathrm{a}$ & $0.06 \mathrm{a}$ & $0.05 \mathrm{a}$ & $0.32 \mathrm{a}$ & $0.29 \mathrm{a}$ & $0.07 \mathrm{a}$ & $0.07 \mathrm{a}$ \\
LOX C6 alcohols & $0.77 \mathrm{a}$ & $0.76 \mathrm{a}$ & $1.36 \mathrm{a}$ & $1.77 \mathrm{a}$ & $0.70 \mathrm{a}$ & $0.55 \mathrm{a}$ & $1.63 \mathrm{a}$ & $1.77 \mathrm{a}$ \\
Total LOX & $11.92 \mathrm{a}$ & $12.14 \mathrm{a}$ & $13.87 \mathrm{a}$ & $14.41 \mathrm{a}$ & $6.40 \mathrm{a}$ & $6.14 \mathrm{a}$ & $37.55 \mathrm{a}$ & $38.07 \mathrm{a}$ \\
\hline saturated C7-C10 aldehydes & $<0.01 \mathrm{a}$ & $<0.01 \mathrm{a}$ & $0.29 \mathrm{a}$ & $0.30 \mathrm{a}$ & $0.01 \mathrm{a}$ & $0.01 \mathrm{a}$ & $0.15 \mathrm{a}$ & $0.18 \mathrm{a}$ \\
mono-unsaturated C7-C10 aldehydes & $0.02 \mathrm{a}$ & $0.02 \mathrm{a}$ & $<0.01 \mathrm{a}$ & $<0.01 \mathrm{a}$ & $0.05 \mathrm{a}$ & $0.04 \mathrm{a}$ & $<0.01 \mathrm{a}$ & $<0.01 \mathrm{a}$ \\
di-unsaturated C7-C10 aldehydes & $<0.01 \mathrm{a}$ & $<0.01 \mathrm{a}$ & $0.24 \mathrm{a}$ & $0.26 \mathrm{a}$ & $0.03 \mathrm{a}$ & $0.02 \mathrm{a}$ & $0.12 \mathrm{a}$ & $0.13 \mathrm{a}$ \\
\hline
\end{tabular}


Overall, the total amount of the molecules originating in the lipoxygenase (LOX) pathway (green and fruity notes of virgin olive oils (VOOs)) is not significantly affected by the application of the ultrasound technology. At the same time, the different classes of VOCs belonging to the LOX cascade are not affected by the application of such technology. Furthermore, no increase of saturated and unsaturated aldehydes was observed. All these data confirm that the ultrasound technology does not affect the volatile profile of the obtained virgin olive oil samples.

On the contrary, even if our experiments are not aimed at highlighting differences due to the cultivar, data in Table 3 clearly confirm that the cultivar affects the concentration of these molecules in the oils. The monocultivar oils obtained from Coratina show contents of molecules from the LOX pathway (up to $38 \mathrm{ppm}$ ) at least three times higher than the other cultivars, with Cellina di Nardò showing the lowest content (approx. 6 ppm). Regarding aldehydes, all cultivars showed negligible amounts of the monounsaturated ones (which are more linked to the oxidative defects), while Ogliarola and Coratina showed amounts of saturated and di-unsaturated aldehydes slightly higher than Peranzana and Cellina di Nardò, with, however, very low amounts.

\subsection{Panel Test}

During this study, the sensorial quality of oil samples was also evaluated by a panel of expert panelists, not only to detect the possible defects as requested by the official procedure to classify the virgin olive oils, but mainly to collect information on specific positive notes.

The overall shape of the product sensory fingerprint is globally unchanged in samples obtained with or without ultrasound (Figure S1), except for the differences in the intensity of the fruity (higher in the sonicated sample) as well as for the perceptions of tomato, almond, artichoke, and leaf. The evaluation of bitterness and pungency, typically linked to the presence of phenolic compounds [27], allowed pointing out that the samples obtained with the aid of ultrasound (US) show a bitterness intensity of $20 \%$ higher than the traditional ones; these latter, on the contrary, are characterized by a greater perception of pungency. Overall, the samples obtained after ultrasound treatment have been defined as more harmonious than the non-sonicated ones by the panel group. The greater intensity of olfactory perceptions is indirect proof of the fact that the mechanical action of cavitation does not damage the enzymatic pathway of the LOX responsible for the positive characteristics of the product. The outcome of the evaluation of taste perceptions (bitterness and pungency) is the signal that the sono-chemical action influences the classes of phenolic compounds that are transferred from the oil paste to the lipid phase.

\section{Materials and Methods}

\subsection{Visual Determination of the Maturity Index (MI)}

The MI was determined during sampling by a panel of experienced evaluators, who assessed the skin and flesh color of the olives according to previous works [28]. Briefly, olives were divided into eight groups according to the characteristics summarized in Table 2 and Figure S1. The official method uses 100 olives and calculates an overall MI value for each sample or group of olives. The MI is calculated using the following equation:

$$
\mathrm{MI}=\sum \mathrm{i}_{\mathrm{i}} \times \mathrm{n}_{\mathrm{i}} / 100
$$

where $i$ is the group number and $n_{i}$ is the number of olives in the group.

Olives were examined by manual cutting of pulp, and then counting the ones belonging to each category (Table 2, Figure 1). The method also involves calibrating other measurements of the fruit, such as weight, size, and diameter. 


\subsection{Oil Yield Evaluation}

The oil yield was expressed as percentage of olive oil obtained by processing $100 \mathrm{~kg}$ of olives. It was evaluated by comparing the total oil content of the fruit (on a fresh matter basis) to the oil residue in the olive pomace derived from both the traditional and innovative extraction systems. The fruit and the pomace oil content (on fresh weight) has been determined in triplicate for each sample by the Soxhlet method [29]. The data are summarized in Figure 2.

\subsection{Oil Production and End-User Validation Protocol}

The oils were produced during the 2017-2018 crop seasons in industrial plants producing olive oil (1500-3000 kg/h) located in three different geographical areas of the Apulia region (Frantoio Mimì, Az. Agricola Donato Conserva Modugno (BA); Frantoio Graco Food, Torremaggiore (FG); Il Frantolio-Cisternino, Ostuni). The extraction plants of the all three mills were provided with a two-phase centrifugal system for oil separation. Two of them were equipped with a hammer crusher, while the third one (Frantoio Graco Food) was also provided with a de-stoner. All the plants had the malaxer hermetically closed, thus reducing the contact the olive paste with oxygen.

The homogeneous batches of olives (cv Coratina, Peranzana, Ogliarola, and Cellina di Nardò) were divided into samples of $800 \mathrm{~kg}$ each. Olives were washed before crushing. The crushed olive paste was then moved into the sono-heat-exchanger (SHE) and then it reached the malaxer. The SHE was characterized by a work capacity of $1500 \mathrm{~kg} / \mathrm{h}$, and it was equipped with 56 transducers (100 watt and $31 \mathrm{kHz}$ ) able to transfer a specific energy equal to 18,000 kJ/kg. Moreover, the SHE was also used to keep the temperature constant $\left(25^{\circ} \mathrm{C}\right)$, thanks to its capability to cool and heat the olive paste. The different olive production lots were treated alternately with or without ultrasounds (i.e., the SHE was activated or not) in order to compare the effect of ultrasounds with respect to the traditional process. After application of the SHE, the malaxer was used as a buffer to continuously feed the decanter; the malaxation time was set at $0 \mathrm{~min}$ for the sonicated samples and at $30 \mathrm{~min}$ for the traditional ones. The resulting EVOO was collected, filtered, weighed (to determine the yields), and stored in dark bottles (500 mL) at $15{ }^{\circ} \mathrm{C}$ until chemical analysis. A total of 23 samples (Table 1) were obtained and analyzed.

\subsection{Evaluation of the European Legal Quality of the Virgin Olive Oils}

Free acidity (\% oleic acid), peroxide value ( $\mathrm{meq}_{\mathrm{O} 2} / \mathrm{kg}$ ), and spectroscopic indices were measured according to the analytical methods described in European regulation 2568/91 and the next amendments and additions [30]. According to the official method (European regulation 2568/91, annex XII, and subsequent amendments), the organoleptic evaluations were carried out by the professional panel group of the University of Bari (panel leader Dr. Alfredo Marasciulo), composed of 11 professional tasters, trained to recognize, describe, and quantify basic taste and odor properties. Olive oils were described through both positive ("fruity", "bitter", and "pungent") and negative (for instance "rancid", "fusty", "musty", and "winey") attributes.

\subsection{HPLC-DAD Analysis of the Phenolic Compounds before and after Acidic Hydrolysis}

Phenolic compounds from olive oils were extracted and analyzed according to the IOC official method [19]. Phenolic compounds were extracted with a $\mathrm{MeOH}: \mathrm{H}_{2} \mathrm{O}$ 80:20 v/v solution and immediately analyzed by an HP1100 system equipped with an autosampler, a column heater module, and a quaternary pump, and coupled to a diode array detector (DAD) (all from Agilent Technologies). A SphereClone ODS(2), $5 \mu \mathrm{m}, 250 \times 4.6 \mathrm{~mm}$ id column was used; elution was performed by using the $\mathrm{H}_{2} \mathrm{O}$ (pH 3.2 by formic acid)/acetonitrile/methanol eluents and using the gradient reported in the IOC method. The injection volume was $20 \mu \mathrm{L}$. Identification was carried out at $280 \mathrm{~nm}$. Syringic acid was used as the internal standard and the content of phenolic compounds was expressed in $\mathrm{mg} / \mathrm{kg}$ of tyrosol. 
The acidic hydrolysis was then applied on the hydroalcoholic extracts to evaluate the total content of free and bound tyrosol and hydroxytyrosol [23]: $300 \mu \mathrm{L}$ of the extract was added with $300 \mu \mathrm{L}$ of $\mathrm{H}_{2} \mathrm{SO}_{4} 1.0 \mathrm{M}$, the mixture was maintained in an oven for $2 \mathrm{~h}$ at $80^{\circ} \mathrm{C}$, diluted using $400 \mu \mathrm{L}$ of water, and analyzed by HPLC-DAD. Analysis was performed using an HP1200 liquid chromatograph equipped with HP DAD (Agilent Technologies). An RP18 column, $150 \times 3 \mathrm{~mm}(5 \mu \mathrm{m})$ Gemini (Phenomenex, Torrance, CA, USA) was used; flow rate was $0.4 \mathrm{~mL} / \mathrm{min}$. The eluents were $\mathrm{H}_{2} \mathrm{O}$ acidified to $\mathrm{pH} 3.2$ with formic acid (A) and acetonitrile (B); the following linear solvent gradient was applied: from $95 \%$ to $70 \% \mathrm{~A}$ in $5 \mathrm{~min}$, to $50 \% \mathrm{~A}$ in $5 \mathrm{~min}$, to $98 \% \mathrm{~B}$ in $5 \mathrm{~min}$, then a plateau of $5 \mathrm{~min}$ and finally to $95 \%$ in $2 \mathrm{~min}$. The total time of analysis was $22 \mathrm{~min}$.

\subsection{HS-SPME-GC-MS Analysis of Volatile Organic Compounds (VOCs)}

The profile of volatile compounds was analyzed by a HS-SPME-GC-MS method, recently developed and validated [24], which allowed quantification of 73 volatile organic compounds (VOCs) using 9 internal standards for area normalization. Briefly, a $4.3 \mathrm{~g}$ aliquot of each EVOO and $0.1 \mathrm{~g}$ of ISTD (internal standard) solution were weighed into $20 \mathrm{~mL}$ screw cap head-space vials, and immediately sealed. A tri-phase Divinylbenzene/Carboxen/Polydimethylsiloxane (DVB/CAR/PDMS) 50/30 $\mu \mathrm{m}$ SPME fiber (Agilent, Palo Alto, CA, USA) was exposed in the vial head-space under orbital shaking for $20 \mathrm{~min}$, after a five-minute equilibration of sample at $45^{\circ} \mathrm{C}$. The adsorbed VOCs were desorbed in $1.7 \mathrm{~min}$ in the injection port (split-less mode, $260^{\circ} \mathrm{C}$ ) of a $6890 \mathrm{~N} \mathrm{GC}$ system, equipped with a MS detector (model 5975, Agilent, Palo Alto, CA, USA) and an HP-Innowax capillary column (50 $\mathrm{m} \times 0.2 \mathrm{~mm}$ i.d., $0.4 \mu \mathrm{m}$ film thickness) was used. The fiber was then conditioned at $260{ }^{\circ} \mathrm{C}$ for $20 \mathrm{~min}$.

Oven temperature program: initial temperature $40{ }^{\circ} \mathrm{C}$ for $2 \mathrm{~min}$, then $4{ }^{\circ} \mathrm{C} / \mathrm{min}$ until $156{ }^{\circ} \mathrm{C}$, then $10{ }^{\circ} \mathrm{C} / \mathrm{min}$ until $260^{\circ} \mathrm{C}$. The carrier gas was helium $1.2 \mathrm{~mL} / \mathrm{min}$; temperature of ion source and transfer line was $230^{\circ} \mathrm{C}$ and $250^{\circ} \mathrm{C}$, respectively. MS detector operated in scan mode in the $\mathrm{m} / \mathrm{z}$ range $30-350 \mathrm{Th}, 1500 \mathrm{Th} / \mathrm{s}$.

Since the response of SPME fibers varies depending upon wearing and sample complexity, the addition of suitable internal standards (ISTDs) to the samples prior to analysis was necessary. An ISTD mix was selected on the basis of chemical similarity to the compounds present in the EVOOs, and contained acetic acid- $\mathrm{d}_{3}$, 6-chloro-2-hexanone, butanol- $\mathrm{d}_{10}$, 4-methyl-2-pentanol, 3-octanone, ethyl acetate- $\mathrm{d}_{8}, 3,4$-dimethylphenol, toluene- $\mathrm{d}_{8}$, and trimethylacetaldehyde in refined olive oil (IntStd). This IntStd was added to both samples and calibration standards before the analysis. Calibration lines (1st order) were built for each analyte in ranges including the concentration present in EVOO samples, using 6 diluted solutions constituted of the same amount of IntStd and different amounts of external standard. Each analyte was referred to the most suitable ISTD. The diluted standard solutions were stored in the dark at $-20{ }^{\circ} \mathrm{C}$ until chromatographic analyses. Refined olive oil was used as a matrix for building the calibration lines. Mass spectra and retention times of injected authentic standards were compared with those of each peak for identification of the 73 VOCs.

\subsection{Statistics}

The analysis was carried out in triplicate and the results were expressed as mean values $(\mathrm{mv})=$ standard deviation (SD). Statistical analysis was performed using Microsoft Excel software. Significant differences between treatments were determined using one-way ANOVA followed by a $t$-test.

\section{Conclusions}

Many solutions for improving quality and oil yields have been proposed during the last decade in the olive oil sector, but only few ideas have been transferred into the market. This paper illustrates the end-user validation of the application of ultrasounds in the extra virgin olive oil extraction process. The currently used technology often considers the oil yields and the quality, associated with 
phenolic content and positive sensorial attributes, in antithesis. The results obtained in this research demonstrated an increase of oil yields and a reduction of the process time with a simultaneous preservation of the product quality, evaluated by validated methods. The total phenols and the total hydroxytyrosol content in EVOOs obtained from traditional milling and using the SHE system were comparable. Analogously, the sum of the molecules originating from the lipoxygenase (LOX) pathway (related to the green and fruity notes of VOOs) was not significantly affected by the application of the ultrasounds. On the contrary, the cultivar seems to affect the concentration of these molecules with highest values for Coratina cv. Anyway, no significant differences were highlighted between oils of the same cultivar obtained with or without the use of ultrasounds.

Overall, the analytical results and the collaboration with the end-users have contributed to the assessment of the machine's usability by specific users.

The validation of the innovation and its transferability to the olive oil sector has been demonstrated by placing the machine in different geographical areas, to study its behavior towards different cultivars and different degrees of maturation. The innovative technology combines the mechanical energy of ultrasounds with the possibility of modulating the thermal exchange of olive paste. It has been demonstrated able: (i) to eliminate the malaxation step by realizing an effectively continuous process, (ii) to raise oil extraction yields recovering a part of EVOO usually lost in olive pomace, (iii) to preserve the antioxidant phenols and volatiles from the LOX pathway responsible for the fruity and green notes of virgin olive oils, (iv) to offer a sustainable plant solution able to reduce the process time and to save energy (coherently with the goals of the 2030 agenda on sustainable development), thus guaranteeing the right income to the manufacturers.

Furthermore, an added value of this work was the demonstration of the applicability of this mobile and flexible prototype machine (the SHE) in different plants produced by the world's leading manufacturers of oil machines. The implementation of the prototype in this sector will contribute to promoting the culture of innovation as a keystone for increasing the competitiveness of the olive oil production chain by developing technological solutions such as ultrasounds to improve the production cycle and the environmental and economic sustainability of the process.

Supplementary Materials: The following are available online, Figure S1: Spider web plot obtained by sensorial analysis of two samples, obtained by the same batch of olives processed with (green in the plot) or without (yellow) the use of ultrasounds.

Author Contributions: Conceptualization, M.L.C. and N.M.; data curation, L.C., M.B., F.C., and G.M.; formal analysis, L.C. and M.B.; project administration, F.C., M.L.C., and N.M.; resources, L.C., M.B., F.C., G.M., M.L.C., and N.M.; supervision, M.L.C. and N.M.; writing-original draft, L.C. and M.B.; writing-review and editing, F.C., M.L.C., and N.M.

Funding: The work was supported by COMPETiTiVE_claims of olive oil to improve the market value project (AGER 2 Project, grant no. 2016-0174) and by a grant of Istituto Nutrizionale Carapelli.

Conflicts of Interest: The authors declare no conflict of interest.

\section{References}

1. Clodoveo, M.L. Industrial Ultrasound Applications in The Extra-Virgin Olive Oil Extraction Process: History, Approaches, and Key Questions. Foods 2019, 8, 121. [CrossRef] [PubMed]

2. Aleem, H.; Zhao, Y.; Lord, S.; McCarthy, T.; Sharratt, P. Pharmaceutical process validation: An overview. Proc. Inst. Mech. Eng. Part E J. Process Mech. Eng. 2003, 217, 141-151. [CrossRef]

3. Katz, P.; Campbell, C. FDA 2011 process validation guidance: Process validation revisited. J. Gxp Compliance 2012, 16, 18.

4. Maropoulos, P.G.; Ceglarek, D. Design verification and validation in product lifecycle. Cirp Ann. 2010, 59, 740-759. [CrossRef]

5. Clodoveo, M.L.; Durante, V.; La Notte, D. Working towards the development of innovative ultrasound equipment for the extraction of virgin olive oil. Ultrason. Sonochemistry 2013, 20, 1261-1270. [CrossRef] [PubMed] 
6. Clodoveo, M.L.; Durante, V.; La Notte, D.; Punzi, R.; Gambacorta, G. Ultrasound-assisted extraction of virgin olive oil to improve the process efficiency. Eur. J. Lipid Sci. Technol. 2013, 115, 1062-1069. [CrossRef]

7. Clodoveo, M.L. An overview of emerging techniques in virgin olive oil extraction process: Strategies in the development of innovative plants. J. Agric. Eng. 2013, 44. [CrossRef]

8. Amirante, R.; Clodoveo, M.L. Developments in the design and construction of continuous full-scale ultrasonic devices for the EVOO industry. Eur. J. Lipid Sci. Technol. 2017, 119, 1600438. [CrossRef]

9. Clodoveo, M.L.; Hbaieb, R.H. Beyond the traditional virgin olive oil extraction systems: Searching innovative and sustainable plant engineering solutions. Food Res. Int. 2013, 54, 1926-1933. [CrossRef]

10. Clodoveo, M.L.; Moramarco, V.; Paduano, A.; Sacchi, R.; Di Palmo, T.; Crupi, P.; Amirante, R. Engineering design and prototype development of a full scale ultrasound system for virgin olive oil by means of numerical and experimental analysis. Ultrason. Sonochem. 2017, 37, 169-181. [CrossRef]

11. Clodoveo, M.L.; Corbo, F.; Amirante, R. Does the Introduction of Ultrasound in Extra-Virgin Olive Oil Extraction Process Improve the Income of the Olive Millers? The First Technology for the Simultaneous Increment of Yield and Quality of the Product. In Technological Innovation in the Olive Oil Production Chain; IntechOpen: London, UK, 2018; Available online: https://www.intechopen.com/online-first/does-theintroduction-of-ultrasound-in-extra-virgin-olive-oil-extraction-process-improve-the-income- (accessed on 24 June 2019). [CrossRef]

12. Roselli, L.; Cicia, G.; Cavallo, C.; Del Giudice, T.; Carlucci, D.; Clodoveo, M.L.; De Gennaro, B.C. Consumers' willingness to buy innovative traditional food products: The case of extra-virgin olive oil extracted by ultrasound. Food Res. Int. 2018, 108, 482-490. [CrossRef] [PubMed]

13. Muraglia, M.; De Bellis, M.; Catalano, A.; Carocci, A.; Franchini, C.; Carrieri, A.; Fortugno, C.; Bertucci, C.; De Saphy, J.F.; De Luca, A.; et al. N-aryl-2,6-dimethylbenzamides, a new generation of tocainide analogues as blockers of skeletal muscle voltage-gated sodium channels. J. Med. Chem. 2014, 57, 2589-2600. [CrossRef] [PubMed]

14. Amirante, R.; Clodoveo, M.L.; Distaso, E.; Ruggiero, F.; Tamburrano, P. A tri-generation plant fuelled with olive tree pruning residues in Apulia: An energetic and economic analysis. Renew. Energy 2016, 89, 411-421. [CrossRef]

15. Restuccia, D.; Clodoveo, M.L.; Corbo, F.; Loizzo, M.R. De-stoning technology for improving olive oil nutritional and sensory features: The right idea at the wrong time. Food Res. Int. 2018, 106, 636-646. [CrossRef] [PubMed]

16. Roselli, L.; Clodoveo, M.L.; Corbo, F.; De Gennaro, B. Are health claims a useful tool to segment the category of extra-virgin olive oil? Threats and opportunities for the Italian olive oil supply chain. Trends Food Sci. Technol. 2017, 68, 176-181. [CrossRef]

17. Clodoveo, M.L.; Dipalmo, T.; Crupi, P.; Durante, V.; Pesce, V.; Maiellaro, I.; Corbo, F.; Franchini, C. Comparison between different flavored olive oil production techniques: Healthy value and process efficiency. Plant Foods Hum. Nutr. 2016, 71, 81-87. [CrossRef]

18. Amirante, P.; Clodoveo, M.L.; Tamborrino, A.; Leone, A. A new designer malaxer to improve thermal exchange enhancing virgin olive oil quality. In Proceedings of the VI International Symposium on Olive Growing 949, Evora, Portugal, 9-13 September 2008; pp. 455-462.

19. International Olive Council (IOC). Determination of Biophenols in Olive Oil by HPLC; IOC/T.20/Doc No. 29; International Olive Council: Madrid, Spain, 2009.

20. Mulinacci, N.; Giaccherini, C.; Ieri, F.; Innocenti, M.; Romani, A.; Vincieri, F.F. Evaluation of lignans and free and linked hydroxy-tyrosol and tyrosol in extra virgin olive oils after hydrolises processes. J. Sci. Food Agric. 2006, 86, 757-764. [CrossRef]

21. Oliveras-López, M.J.; Innocenti, M.; Giaccherini, C.; Ieri, F.; Romani, A.; Mulinacci, N. Study of the phenolic composition of Spanish and Italian monocultivar extra- virgin olive oils: Distribution of lignans, secoiridoids, simple phenols and flavonoids. Talanta 2007, 73, 726-732. [CrossRef]

22. Tsimidou, M.Z.; Sotiroglou, M.; Mastralexi, A.; Nenadis, N.; Garcìa-Gonzàlez, D.L.; Gallina Toschi, T. In House Validated UHPLC Protocol for the Determination of the Total Hydroxytyrosol and Tyrosol Content in Virgin Olive Oil Fit for the Purpose of the Health Claim Introduced by the EC Regulation 432/2012 for “Olive Oil Polyphenols”. Molecules 2019, 24, 1044. [CrossRef] 
23. Bellumori, M.; Cecchi, L.; Innocenti, M.; Clodoveo, M.L.; Corbo, F.; Mulinacci, N. The EFSA health claim on olive oil polyphenols: Acid hydrolysis validation and total hydroxytyrosol and tyrosol determination in Italian virgin olive oils. Molecules 2019, 24, 2179. [CrossRef]

24. Fortini, M.; Migliorini, M.; Cherubini, C.; Cecchi, L.; Calamai, L. Multiple internal standard normalization for improving HS-SPME-GC-MS quantitation in virgin olive oil volatile compounds (VOO-VOCs) profile. Talanta 2017, 165, 641-652. [CrossRef]

25. Privitera, M.B.; Evans, M.; Southee, D. Human factors in the design of medical devices-approaches to meeting international standards in the European Union and USA. Appl. Ergon. 2017, 59, 251-263. [CrossRef] [PubMed]

26. Tsimidou, M.Z.; Nenadis, N.; Servili, M.; García-González, D.L.; Gallina Toschi, T. Why tyrosol derivatives have to be quantified in the calculation of "olive oil polyphenols" content to support the health claim provisioned in the EC Reg. 432/2012. Eur. J. Lipid Sci. Technol. 2018, 120, 1800098. [CrossRef]

27. Campestre, C.; Angelini, G.; Gasbarri, C.; Angerosa, F. The compounds responsible for the sensory profile in monovarietal virgin olive oils. Molecules 2017, 22, 1833. [CrossRef] [PubMed]

28. Guzmán, E.; Baeten, V.; Pierna, J.A.F.; García-Mesa, J.A. Determination of the olive maturity index of intact fruits using image analysis. J. Food Sci. Technol. 2015, 52, 1462-1470. [CrossRef] [PubMed]

29. Cecchi, L.; Bellumori, M.; Cipriani, C.; Mocali, A.; Innocenti, M.; Mulinacci, N.; Giovannelli, L. A two-phase olive mill by-products (pâté) as a convenient source of phenolic compounds: Content, stability, and antiaging properties in cultured human fibroblasts. J. Funct. Foods 2018, 40, 751-759. [CrossRef]

30. European Economic Community. Commision Regulation (EEC) No. 2568/91 of 11 July 1991 on the characteristic of olive oil and olive-residue oil and on the relevant methods of analysis. EU Regulation 2568. Off. J. Eur. Com. Legis 1991, L24, 1-140.

Sample Availability: Samples of the compounds are not available from the authors.

(C) 2019 by the authors. Licensee MDPI, Basel, Switzerland. This article is an open access article distributed under the terms and conditions of the Creative Commons Attribution (CC BY) license (http://creativecommons.org/licenses/by/4.0/). 